\title{
"Please bring a plate": A metaphor for learning advisor practice based on Pacific values
}

\author{
Suzanne Manning \\ Whitereia/Weltec, New Zealand \\ Email: suzanne.manning@whitireia.ac.nz
}

\begin{abstract}
Metaphors are powerful devices for guiding the practice of learning advisors and are often used implicitly. However, personal metaphors can also mis-guide or constrain thinking about practice by encouraging a monocultural perspective. A paper by Golding et al. (2015) evaluated a variety of metaphors for their usefulness in guiding the practice of learning advisors. These evaluated metaphors have their origins in a Palagi or Western cultural worldview, dominant in Aotearoa New Zealand as a result of colonisation. This paper reports on a personal philosophical enquiry process, where I attempt to develop a metaphor that would help me, as a Palagi learner advisor, appreciate the Pacific worldview and potentially work with Pacific students in a more culturally responsive way. The developed metaphor is based on helping someone bake for a 'bring a plate' function, a social event where everyone invited provides food to share. It is based on my experiences, while also seeking to incorporate values embedded in Pacific cultures. This metaphor is offered as a contribution to philosophical discussions of learning advising: it is my 'plate' to help feed our academic community.
\end{abstract}

Keywords: learning advising, teaching and learning, Pacific, culturally-responsive pedagogy

\section{Metaphors for culturally responsive pedagogy}

Learning Advisors often use metaphor (implicitly or explicitly) to understand their practice and help them judge what to do ... Yet Learning Advisors seldom evaluate whether their metaphors clarify or obscure their practice. (Golding et al., 2015, p. 1)

Having defined the problem in the quote above, Golding et al. (2015) proceed to evaluate the coherence of a range of metaphors with the pedagogy of one-on-one learning advising (for example, the learning advisor as a fixer, doctor, or guide). The authors' pedagogical approach 
was supporting and improving student learning by assisting students to develop skills, confidence and understanding in order to be independent learners. The paper highlights the values of equity, inclusivity and sustainability with limited resources as being important to learning advising. Other principles include providing central, not peripheral support for academic learning, and enabling students to be active in their own academic development by encouraging reciprocal relationships.

Golding et al. (2015) conclude that the most useful metaphors emphasise co-creation, where power is shared between the learning advisor and student. This paper does not disagree with the conclusions reached in that paper; rather it highlights a silence: the absence of metaphors that might resonate more with people from non-Western cultures. Specifically, this paper investigates metaphors that might resonate with people of Pacific cultural backgrounds. I therefore use the Samoan term 'Palagi' to describe both the Western viewpoint and my positioning as a New Zealander of English settler background.

The reason for highlighting the monocultural nature of the metaphors presented by Golding et al. (2015) is that culturally responsive pedagogy requires learning advisors to take account of students' cultural backgrounds and worldviews (MaUa-Hodges, 2018). This includes awareness of one's own worldviews and a conscious effort to understand the worldviews of others. In this pedagogy, the teaching relationship is based on connecting and communicating through the students' cultural values. Culturally responsive pedagogy has been shown to strengthen learning outcomes for students (MaUa-Hodges, 2018).

When the cultural backgrounds of the learning advisor and the student are dissimilar, culturally responsive pedagogy becomes a challenge. As an example, to be culturally responsive towards Pacific students, a Palagi learning advisor needs to understand the worldviews and values of Pacific cultures. For those learning advisors, like myself, who have had little prior contact with Pacific cultures, this understanding must come from an active process of research and assimilation. This paper is the outcome of my personal search for a more in-depth understanding of Pacific cultures and their values, in order to improve the cultural responsiveness of my practice. I have done this by taking up the suggestion of Golding et al. (2015) to create and evaluate my own personal practice metaphor. 
A metaphor is a linguistic device to aid the understanding of complex concepts. Jensen (2006) used the metaphor of a bridge to describe the work that a metaphor does: linking characteristics of a familiar thing (vehicle term) with something else (topic term), drawing on previous knowledge to aid understanding of the topic term. The specific characteristics being linked often comprise assumed knowledge. When this assumed knowledge is obvious to everyone, the metaphor is said to be active (Farquhar \& Fitzsimons, 2016; Jensen, 2006). However, assumed knowledge is culturally and contextually dependent (Farquhar \& Fitzsimons, 2016) and this can cause issues for culturally responsive pedagogy.

Metaphors have the power to shape thinking about a concept, and guide people to focus on particular features, presumably the most important ones (Golding et al., 2015). The trade-off is, as Lakoff and Johnson (2003 [1980]) caution, that metaphors "highlight some features of reality and hide others. The acceptance of metaphor ... forces us to focus only on those aspects of our experience that it highlights" (p. 157, emphasis in the original). Therefore, a metaphor to guide the culturally responsive practice of a Palagi, advising a Pacific student, must highlight those aspects of experience that resonate with Pacific cultural values.

This paper is the result of a personal philosophical enquiry to develop a metaphor for my practice as a Palagi learning advisor working with Pacific students. This enquiry, like the process undertaken by Golding et al. (2015), is based on a reiterative process of formulating an idea, inviting discussion and feedback, and reformulation. I sought feedback from close colleagues of both Pacific and non-Pacific backgrounds, and at the Association for Tertiary Learning Advisors of Australia and New Zealand conferences, during 2018.

This introduction has provided the background to the enquiry. The next section outlines Pacific cultural values as represented by published literature and by my Pacific colleagues. The following section presents the metaphor that I have developed. It is based on my personal experience of participating in 'bring a plate' functions and helping others to participate as well. First the context of these functions is explained, followed by the metaphor, and then an explanation of the metaphor linked to learning advisor practice. The metaphors are then evaluated against Pacific and Palagi cultural values. 


\section{Pacific cultural values}

Pacific writers often refer to Pacific values or the 'Pacific Way', which indicates the importance of values to people of Pacific cultures (Huffer, 2006; Johansson-Fua, Ruru, Sanga, Walker \& Ralph, 2012). Here I privilege the voices of Pacific authors explaining their cultural values. Te Ava, Arini and Rubie-Davies (2011) suggested teaching activities based on values of teamwork, hard work, respect and achievements; Johansson-Fua et al. (2012) highlighted the values of "responsibility/loyalty, maintaining reciprocal relationships, and compassion/ humility/ willingness" (p. 254) and Chu, Samala Abella and Paurini (2013) referred to values of "respect, compassion, humility, honesty, integrity, trustworthiness and reciprocity" (p. 7). Huffer (2006) concluded

"that common values in the Pacific revolve around concepts of solidarity and reciprocity; the fostering and maintenance of kinship networks and relationships; attachment to land and sea; respect and care for others; the upholding of human dignity; and consultation and shared leadership" (p. 50).

From this selected literature, Pacific values can be seen to emphasise a collective approach and the strong importance of relationships and community.

Pacific metaphors make links to nature, land, families, and traditions. These metaphors are active for Pacific peoples, who need little explanation to understand the connection between the vehicle terms, such as the Fonofale (Samoan house), Kakala (Tongan flower necklace), or Tivaevae (Cook Island quilt), and the topic term (for example, Albon, 2015; Johansson-Fua et al., 2012; Pulotu-Endermann, 2001; Sanga, 2014). The coconut or niu is an example of a universal Pacific metaphor because of its significance to many Pacific islands (Albon, 2015). When a Pacific learning advisor uses such metaphors with Pacific students, they are likely to be active metaphors and contribute to a culturally responsive connection between learning advisor and student. In contrast, these Pacific metaphors are not likely to be active for a Palagi learning advisor. The appropriateness of a Palagi learning advisor, such as myself, using Pacific metaphors as a personal metaphor for practice was questioned when I presented this idea at a seminar in 2018. An alternative approach was suggested to me by Teremoana MaUa-Hodges and Leautuli'ilagi Sauvao, and that was to develop a personal metaphor based on both Pacific values and my own cultural background. 
In order to encapsulate Pacific values, the focus of such a personal metaphor should be on collective endeavour and emphasise community relationships. The metaphors suggested by Golding et al. (2015) all focused on the role of an individual learning advisor, and the vehicle terms such as 'fixer' and 'teacher' were individual job titles, reflecting a individualist Palagi worldview. In contrast, a Pacific worldview takes a different position. Therefore, instead of using the starting phrase 'a learning advisor is like a...', I chose to use the phrase 'the process of learning advising is like...', to shift the focus from the individual role to a joint process.

\section{The 'bring a plate' metaphor}

The metaphor I developed through this philosophical process of enquiry is:

The process of learning advising is like ...helping someone prepare baking for a 'bring a plate' function.

This metaphor is based on the knowledge of 'bring a plate' gatherings. These are group social events, where guests are all expected to bring some food to share. It was, and still is, a feature of Palagi culture in New Zealand. During my younger years, there was an expectation of home baking; in modern times it has become more acceptable to bring shop-bought goods, although home baking is given higher status at the function. As a child, I was taught by my mother and my grandmother how to bake. Sometimes the baking was for our family, but more often it was for a 'bring a plate' function. In turn I taught my children to bake, so that they, too, could be prepared to participate in such functions. This metaphor is based on my experiences of teaching others to produce home baking for consumption at a social event.

Firstly, the trainee baker will be following a recipe; something that will have been written by an experienced baker and should be suited to the level of skill of the trainee. The baking tutor should have a written copy of the recipe, rather than receive the trainee's verbal account of it. This is so they can help interpret the recipe for the trainee, given their greater knowledge of how to bake and read recipes. If substitution of ingredients is required, for example, the tutor can advise the trainee on the best options. 
To be a good baker, a core set of skills needs to be learnt, alongside the more advanced skills used in specific recipes. Core skills include health and safety practices, such as hand washing and using clean equipment, which must be reinforced for trainee bakers. The tutor needs to assess the level of skill of the trainee baker and adapt their advice given accordingly. In some cases, the tutor may give verbal advice only, while the trainee does the baking. At other times, the tutor may demonstrate techniques while the trainee observes. The tutor may even guide the hands of the trainee baker if necessary. When the tutor works with a trainee on a number of occasions, it would be expected that the trainee gradually learns to do more of the baking themselves, adhere to health and safety practices routinely, and need less advice to produce an acceptable product. The tutor needs to judge how to manage that transition.

An important part of this metaphor is that the baking is being produced for a purpose: to take to a public function, where it will be on display and then consumed by other people. Doing the baking might be fun for the trainee and a learning experience in itself, yet it is not the only aim of the activity. A safe, edible and well-presented end-product for the wider community is the mark of success.

In this metaphor, the trainee baker is the student and the tutor is the learning advisor. The recipe is the assignment descriptor, written using conventional academic language that the learning advisor should understand and be able to interpret for the student. The learning advisor, like the baking tutor, needs to assess the skill level of the student and adjust their advice accordingly. This can range from suggesting areas of work to revise through to giving examples of how to reword a sentence. Core skills such as paragraph writing, and writing introductions and conclusions, need to be mastered by all students. Referencing and academic integrity are important practices that can be likened to paying attention to health and safety issues. Finally, an 'edible' assignment is one that has followed the instructions and answered the questions, a 'tasty' assignment is one that has well-thought out content, and a 'wellpresented' assignment has correct formatting, spelling and grammar. 


\section{Evaluating the metaphor}

This 'bring a plate' metaphor can be evaluated against two different sets of values: Pacific and Palagi. As applied to learning advising, these two sets of values are complementary but not the same. Pacific writers discuss the importance of maintaining reciprocal relationships and community networks, and elevate concern for others above individual expression (for example see Te Ava et al., 2011). For Pacific peoples, caring and respect for others is a paramount value. From a Palagi perspective, Golding et al. (2015) evaluated their selected metaphors against a set of values and principles they developed as part of their philosophical enquiry, which included a focus on empowering students to be independent learners, working in partnership with students to develop academic skills, and placing learning advising as a central support for all students.

When the Pacific values are foregrounded, the metaphor of helping a trainee baker prepare for a 'bring a plate' function places an emphasis on the context. It does not suffice for a trainee to go through the motions of baking without producing an acceptable end product. The tutor aims to help the trainee produce food that is safe to eat by others, tasty to eat and well presented. An acceptable 'plate' for the function is required in order for the trainee to contribute to the community event and to show respect for the others in the community. These are important values in a Pacific context. The student receives feedback from the community and not just the tutor, further reinforcing the concept that the purpose of the baking is caring for others. Reciprocal relationships are developed between both the tutor and the trainee, and the trainee and the community, through this process. The aim of supporting the trainee to be an independent baker is seen in the context of being able to take their place as a contributing community member.

In terms of learning advising seen through Pacific values, this metaphor suggests that a learning advisor should emphasise the importance of ensuring the student assignment is as good as possible, for example, based on quality research, is well-constructed and referenced, and is presented well. It also suggests that the learning advisor would highlight to the student that the purpose of a good assignment is not just related to their individual grades; it is also about being respectful towards the academic community they are becoming part of. In this view academic integrity and avoiding plagiarism is more about respect for others than about following pedantic rules. 
When the Palagi values are foregrounded in this metaphor, there is an emphasis on individualism and independence. The tutor assesses the prior skills and knowledge of the trainee baker and adjusts the help given as required, giving maximum opportunity for the trainee to do the baking independently. However, emphasis on the individual and their ability to work independently can mean that the importance of the end-product to the community becomes secondary. Further, the primary relationship from a Palagi perspective tends to be presented as a dyad between learning advisor and student, rather than being seen as a threeway relationship of learning advisor, student and community. The actual process of guiding the trainee might be similar when viewed through Palagi or Pacific lenses, yet the expectations and underlying values communicated to the trainee are different.

\section{Using metaphors to guide personal practice}

This article has responded to the challenge set by Golding et al. (2015) to create and evaluate personal metaphors, as they had found the creation and evaluation process itself to be a valuable reflection tool. Metaphorical thinking is a part of everyday life, and most people use implicit metaphors to guide them in their daily life (Golding et al., 2015; Jensen, 2006; Lakoff \& Johnson, 2003 [1980]). However, using personal metaphors can also be limiting or unhelpful, if these metaphors are not explicitly examined and evaluated.

The personal metaphor presented here is a result of a year-long exploration of metaphors that might support me to be more culturally responsive with respect to Pacific students, by highlighting for me the central importance of community-oriented values within Pacific cultures. Working with Pacific students requires me to consider them in the context of an academic community, rather than focusing on them as individual and independent learners.

My journey started by exploring Pacific metaphors that were found to be ineffective, as the terms did not resonate with my experience. The investigation then focused on Pacific values, and how they could be incorporated into a metaphor drawn from my own background. Pacific values emphasise reciprocal community relationships, and respect and caring for others (for example, Johansson-Fua et al., 2012; Te Ava et al., 2011). Individualism and independence are secondary considerations in a Pacific world view. My challenge was to develop a 
metaphor that emphasised a community context while still acknowledging my primary relationship is with the student.

The metaphor of helping someone to prepare for a 'bring a plate' function was how I resolved this tension. Functions where one is expected to 'bring a plate' are a part of the fabric of my community and are bound by expectations of differing but valued contributions to the event, and striving for quality products. As this process is part of my cultural heritage, this metaphor is easy for me to understand. There is no suggestion here that this metaphor will resonant with all Palagi learning advisors. It is offered as the end point of a personal enquiry, as an example of ways that might broaden thinking to encompass other cultural worldviews. Golding et al. (2015) suggested that "readers may be better off treating this article as a prompt for creating and evaluating their own metaphors" (p. 12), and that is probably the best way to treat this article as well.

\section{Acknowledgements}

I would like to acknowledge and thank Teremoana MaUa-Hodges and Leautuli'ilagi Sauvao for sharing their wisdom and thinking with me, teaching me about their Pacific cultures, and helping me to develop this paper. I would also like to acknowledge participants at the ATLAANZ Central Region hui in June 2018 and the ATLAANZ conference in December 2018, who gave me valuable feedback on the ideas for this paper.

\section{References}

Albon, G. (2015). Pasifika leadership programme: Unpacking a cultural metaphor. Retrieved from http://blog.core-ed.org/blog/2015/11/pasifika-leadership-programme-unpacking-a-culturalmetaphor.html

Chu, C., Samala Abella, I., \& Paurini, S. (2013). Educational practices that benefit Pacific learners in tertiary education. Retrieved from Ako Aotearoa website: https://ako.ac.nz/knowledgecentre/pasifika-learner-success-tertiary-education/educational-practices-that-benefit-pacificlearners-in-tertiary-education/

Farquhar, S., \& Fitzsimons, P. (2016). Seeing through the metaphor: The OECD toolbox for early childhood. Semiotica, 2016(212), 97-110. https://doi.org/10.1515/sem-2016-0134

Golding, C., Adam, L., Scott, C., Acheson, C., Johnson, K., Brook, P., . . Kumar, V. (2015). Fix, build, diagnose or guide? Evaluating the metaphors for learning advisors. Association of Tertiary Learning Advisors Aotearoa/New Zealand Journal, 1(1), 1-15.

https://doi.org/10.26473/atlaanz.2015.1.1/001 
Huffer, E. (2006). Regionalism and cultural identity: Putting the Pacific back into the plan. In S. Firth (Ed.), Globalisation and governance in the Pacific Islands (pp. 43-58). ANU E Press.

Jensen, D. (2006). Metaphors as a bridge to understanding educational and social contexts.

International Journal of Qualitative Methods, 5(1), 36-54.

https://doi.org/10.1177/160940690600500104

Johansson-Fua, S., Ruru, D., Sanga, K., Walker, K., \& Ralph, E. (2012). Creating mentorship metaphors: Pacific Island perspectives. LEARNing Landscapes, 6(1), 241-259.

Lakoff, G., \& Johnson, M. (2003 [1980]). Metaphors we live by. Chicago, IL: University of Chicago Press.

MaUa-Hodges, T. (2018). 'Aere! 'Aere! 'Opara ki mua! Teaching Cook Islands Māori to adults in New Zealand: A critical review of literature. Unpublished Master of Professional Practice thesis. Whitireia NZ, Porirua.

Pulotu-Endermann, F. K. (2001). Fonofale model of health. Retrieved from www.hauora.co.nz/resources/Fonofalemodelexplanation.pdf

Sanga, K. (2014). Indigenous Pacific emerging educational metaphors. The International Journal of Diversity in Education, 12(4), 39-52. https://doi.org/10.18848/2327-0020/CGP/v12i04/40084

Te Ava, A., Arini, \& Rubie-Davies, C. (2011). Akarakara akaouanga i te kite pakari o te kuki airani: Culturally responsive pedagogy. Asian-Pacific Education, 23(2), 117-128. Retrieved from

http://ndhadeliver.natlib.govt.nz/delivery/DeliveryManagerServlet?dps_pid=IE13467539 